\title{
Hsp90 inhibitor NVP-AUY922 enhances the radiation sensitivity of lung cancer cell lines with acquired resistance to EGFR-tyrosine kinase inhibitors
}

\author{
SHINSUKE HASHIDA ${ }^{1,2}$, HIROMASA YAMAMOTO ${ }^{1}$, KAZUHIKO SHIEN $^{1,2}$, TOMOAKI OHTSUKA $^{1}$, \\ KEN SUZAWA $^{1}$, YUHO MAKI ${ }^{1}$, MASASHI FURUKAWA ${ }^{1}$, JUNICHI SOH ${ }^{1}$, HIROAKI ASANO ${ }^{1}$, \\ KAZUNORI TSUKUDA $^{1}$, SHINICHIRO MIYOSHI ${ }^{1}$, SUSUMU KANAZAWA $^{3}$ and SHINICHI TOYOOKA ${ }^{1,2}$ \\ Departments of ${ }^{1}$ Thoracic, Breast and Endocrinological Surgery, ${ }^{2}$ Clinical Genomic Medicine and ${ }^{3}$ Radiology, \\ Okayama University Graduate School of Medicine, Dentistry and Pharmaceutical Sciences, Okayama 700-8558, Japan
}

Received September 17, 2014; Accepted December 18, 2014

DOI: 10.3892/or.2015.3735

\begin{abstract}
Acquired resistance to epidermal growth factor receptor (EGFR)-tyrosine kinase inhibitors (TKIs) is a critical issue that needs to be overcome in the treatment of patients with non-small cell lung cancer (NSCLC) harboring EGFR activating mutations. EGFR and AKT are client proteins of the $90-\mathrm{kDa}$ heat shock protein (Hsp90). Therefore, it was hypothesized that the use of Hsp90 inhibitors might allow the resistance to EGFR-TKIs to be overcome. Furthermore, Hsp90 inhibitors are known to function as radiosensitizers in various types of cancer. In the present study, we evaluated the radiosensitizing effect of the novel Hsp90 inhibitor, NVP-AUY922 (AUY), on NSCLC cell lines harboring EGFR activating mutations and showing acquired resistance to EGFR-TKIs via any of several mechanisms. We used HCC827 and PC-9, which are NSCLC cell lines harboring EGFR exon 19 deletions, and gefitinib-resistant sublines derived from the same cell lines with T790M mutation, MET amplification or stemcell like properties. AUY was more effective against the gefitinib-resistant sublines with T790M mutation and MET amplification than against the parental cell lines, although the subline with stem cell-like properties showed more than a 10-fold higher resistance to AUY than the parental cell
\end{abstract}

Correspondence to: Dr Shinichi Toyooka, Department of Clinical Genomic Medicine, Okayama University Graduate School of Medicine, Dentistry and Pharmaceutical Sciences, 2-5-1 Shikata-cho, Kita-ku, Okayama 700-8558, Japan

E-mail: toyooka@md.okayama-u.ac.jp

Abbreviations: Hsp90, 90-kDa heat shock protein; AUY, NVPAUY922; EGFR, epidermal growth factor receptor; TKI, tyrosine kinase inhibitor; NSCLC, non-small cell lung cancer; IR, ionizing radiation; $\mathrm{IC}_{10}$ and $\mathrm{IC}_{50}, 10 \%$ and 50\% inhibitory concentrations; DNA DSB, DNA double-strand break

Key words: NVP-AUY922, 90-kDa heat shock protein inhibitor, epidermal growth factor receptor-tyrosine kinase inhibitor, drug resistance, radiation line. AUY exerted a significant radiosensitizing effect on the parental cell line and the $M E T$-amplified subline through inducing $\mathrm{G}_{2} / \mathrm{M}$ arrest and inhibition of non-homologous end joining (NHEJ). In contrast, the radiosensitizing effect of AUY was limited on the subline with stem cell-like properties, in which it did not induce $\mathrm{G}_{2} / \mathrm{M}$ arrest or inhibition of NHEJ. In conclusion, combined inhibition of Hsp90 plus radiation was effective, and therefore a promising treatment alternative for overcoming major EGFR-TKI resistance, such as that induced by T790M mutation or MET amplification. However, other approaches are required to overcome minor resistance to EGFR-TKIs, such as that observed in cells with stem cell-like properties.

\section{Introduction}

Lung cancer is the leading cause of cancer-related death worldwide (1). To improve the outcomes of patients with lung cancer, various novel therapeutic agents have been developed, including epidermal growth factor receptor (EGFR)-tyrosine kinase inhibitors (TKIs). EGFR-TKIs show significant efficacy against non-small cell lung cancers (NSCLCs) harboring EGFR mutations, by inhibiting EGFR-AKT signaling (2-4). However, most of these tumors eventually acquire resistance to EGFR-TKIs $(5,6)$. Several mechanisms of acquired resistance to EGFR-TKIs have been identified, such as secondary EGFR T790M (7) and minor mutations (8), and MET amplification (9). In addition, we also previously demonstrated an association between resistance to EGFR-TKIs and stem celllike properties of the cells (10).

The $90-\mathrm{kDa}$ heat shock protein (Hsp90) is a chaperone protein that modulates degradation, folding, and/or transport of a diverse set of critical cellular regulatory proteins (11). Critical oncogenic proteins, including receptor tyrosine kinases (RTKs) (e.g. EGFR) and their downstream proteins (e.g. AKT) are client proteins of Hsp90 $(12,13)$, and mutated oncogenic proteins are more dependent on the functions of Hsp90 (14). Therefore, it was considered that Hsp90 may be a therapeutic target to overcome the resistance to EGFR-TKIs. Actually, Hsp90 inhibitors are effective against EGFR-mutated cell lines, even in those 
that are resistant to EGFR-TKIs (15-17). Furthermore, Hsp90 inhibitors are known to exert a radiosensitizing effect through hypoxia-inducible factor- $1 \alpha$ (HIF-1 $\alpha$ ), ataxia-telangiectasia mutated (ATM), checkpoint kinase 1 (CHK1), WEE1 $\mathrm{G}_{2}$ checkpoint kinase (WEE1) (18-21) and other radioresistancerelated client proteins. The radiosensitizing potential of $\mathrm{Hsp} 90$ inhibitors has been evaluated previously in NSCLC cell lines such as A549 and NCI-H460 $(22,23)$. However, there are no reports focusing on the radiosensitizing effect of Hsp90 inhibitors on EGFR-mutated NSCLCs with acquired resistance to EGFR-TKIs.

In the present study, we evaluated the effect of the novel Hsp90 inhibitor NVP-AUY922 (AUY) in overcoming the major mechanisms of acquired resistance to EGFR-TKIs, such as EGFR T790M mutation and MET amplification, and the radiosensitizing effect of this compound. We also studied the radiosensitizing effect of AUY in overcoming acquired resistance induced by the acquisition of stem cell-like properties of the cells.

\section{Materials and methods}

Cell lines and reagents. EGFR-mutant cell lines HCC827 (exon19 del. E746-A750), and PC-9 (exon 19 del. E746-A750) were used. HCC 827 was kindly gifted by Dr Adi F. Gazdar (The University of Texas Southwestern Medical Center, Dallas, TX, USA), who established this line with Dr John D. Minna $(24,25)$. PC-9 was obtained from Immuno-Biological Laboratories (Takasaki, Gunma, Japan). Their gefitinib-resistant sublines, HCC827-GRmet with MET amplification, HCC827-GRstem with stem-cell like properties, and PC-9-GRt790m harboring the EGFR T790M mutation, were previously established by our group (10). All the cell lines were cultured in RPMI-1640 medium supplemented with $10 \%$ fetal bovine serum (FBS), and grown in a humidified incubator with $5 \% \mathrm{CO}_{2}$ at $37^{\circ} \mathrm{C}$. AUY was obtained from Novartis Pharmaceuticals (Basel, Switzerland) and dissolved in dimethyl sulfoxide (DMSO) at the concentration of $10 \mathrm{mM}$ as a stock solution and stored at $-20^{\circ} \mathrm{C}$ until they were used for the in vitro experiments.

Cell proliferation assays. The proliferative ability of the cells was determined by a modified MTS assay using CellTiter $96^{\circledR}$ AQueous One solution reagent (Promega, Madison, WI, USA), as previously reported (26). The antiproliferative effects of AUY were determined based on the $10 \%$ and $50 \%$ inhibitory concentration $\left(\mathrm{IC}_{10}\right.$ and $\left.\mathrm{IC}_{50}\right)$, which denote the concentrations of AUY required to inhibit cell proliferation by $10 \%$ and $50 \%$, respectively.

Clonogenic cell survival assays. Specified numbers of cells were seeded into each well in 6-well tissue culture plates, and after the cells became adherent $(12 \mathrm{~h})$, they were exposed to various concentrations of $\mathrm{AUY}$, according to the obtained $\mathrm{IC}_{10}$ values, which were determined by cell proliferation assays. After a 24-h drug exposure, the plates were irradiated at 2, 4 or 6 Gy (ionizing radiation; IR), followed immediately by replacement of the culture medium with a drug-free conditioned medium. At 14 days after the IR, the colonies were fixed and stained using $0.4 \%$ crystal violet. The number of colonies containing at least 50 cells was counted. The survival data were
Table I. Inhibitory concentration values of NVP-AUY922.

\begin{tabular}{llrr}
\hline Cell lines & \multicolumn{1}{c}{$\begin{array}{c}\text { Resistant } \\
\text { mechanism }\end{array}$} & $\begin{array}{r}\mathrm{IC}_{10} \\
(\mathrm{nM})\end{array}$ & $\begin{array}{r}\mathrm{IC}_{50} \\
(\mathrm{nM})\end{array}$ \\
\hline HCC827 & - & 2.5 & 21.0 \\
HCC827-GRmet & MET amplification & 2.7 & 7.0 \\
HCC827-GRstem & Stem cell-like features & 14.0 & 402.0 \\
PC-9 & - & 2.8 & 9.1 \\
PC-9-GRt790m & T790M mutation & 2.9 & 6.7 \\
\hline
\end{tabular}

$\mathrm{IC}_{10}$ and $\mathrm{IC}_{50}, 10 \%$ and $50 \%$ inhibitory concentration values.

fitted to a linear quadratic model as previously reported (23): $\mathrm{SF}=\exp \left(-\alpha X-\beta X^{2}\right)$, where $S F$ is the survival fraction, $X$ is the radiation dose, and $\alpha$ and $\beta$ are the fitted parameters. The results were evaluated using the surviving cell fractions at $2 \mathrm{~Gy}$ (SF2) and the radiation doses required for $10 \%$ survival $\left(D_{10}\right)$, and the radiosensitizing effects of AUY were evaluated using the ratio of the $D_{10}$ of the control cells to the $D_{10}$ for each AUY concentration.

Cell cycle analysis. The cell cycle distribution was evaluated by propidium iodide staining-based assay using the CycleTest $^{\mathrm{TM}}$ Plus DNA reagent kit and FACSCalibur ${ }^{\mathrm{TM}}$ (both from Becton Dickinson, Franklin Lakes, NJ, USA). The cells were irradiated at 0 or $6 \mathrm{~Gy}$ (IR) after exposure or no exposure to $100 \mathrm{nM}$ AUY for $24 \mathrm{~h}$. At $48 \mathrm{~h}$ after IR, the cells were harvested and analyzed. Doublets, cell debris and fixation artifacts were gated out, and cell cycle analysis was performed using the software, CellQuest ${ }^{\mathrm{TM}}$, ver. 3.1.

Immunofluorescence staining for phosphorylated histone $H 2 A X(\gamma H 2 A X)$. DNA double-strand breaks (DNA DSBs) were evaluated by immunofluorescence staining for $\gamma \mathrm{H} 2 \mathrm{AX}$ (27). Each cell line was plated into chamber slides and after allowing the cells to become adherent $(12 \mathrm{~h})$, the medium was changed to that containing or not containing $100 \mathrm{nM}$ of AUY. After a 24-h drug exposure, the plates were irradiated at $6 \mathrm{~Gy}$, followed immediately by a change of the medium to a drugfree conditioned medium. The cells were fixed in $4 \%$ formalin for $15 \mathrm{~min}$ at 6,24 and $48 \mathrm{~h}$ after the IR. Permeabilization and blocking were performed for $1 \mathrm{~h}$ using 10X PBS with 5\% goat serum and $0.3 \%$ Triton X-100. Anti- $\gamma \mathrm{H} 2 \mathrm{AX}$ antibody at a 1:200 dilution was added as the primary antibody (Millipore, Billerica, MA, USA), followed by incubation overnight at $4^{\circ} \mathrm{C}$. Goat anti-mouse IgG conjugated Alexa Fluor ${ }^{\circledR} 555$ (Life Technologies, Carlsbad, CA, USA) at a 1:1,000 dilution was added as the secondary antibody for $1 \mathrm{~h}$ and DAPI staining was performed using ProLong ${ }^{\circledR}$ Gold antifade reagent with DAPI (Life Technologies). The number of $\gamma \mathrm{H} 2 \mathrm{AX}$ foci in each nucleus was counted in at least 30 cells in each sample.

Statistical analysis. The Mann-Whitney U test was used to compare the data between the 2 groups. Data are expressed as the means \pm standard deviations. Probability values $(\mathrm{P})<0.05$ were considered to indicate statistical significance. All the data 

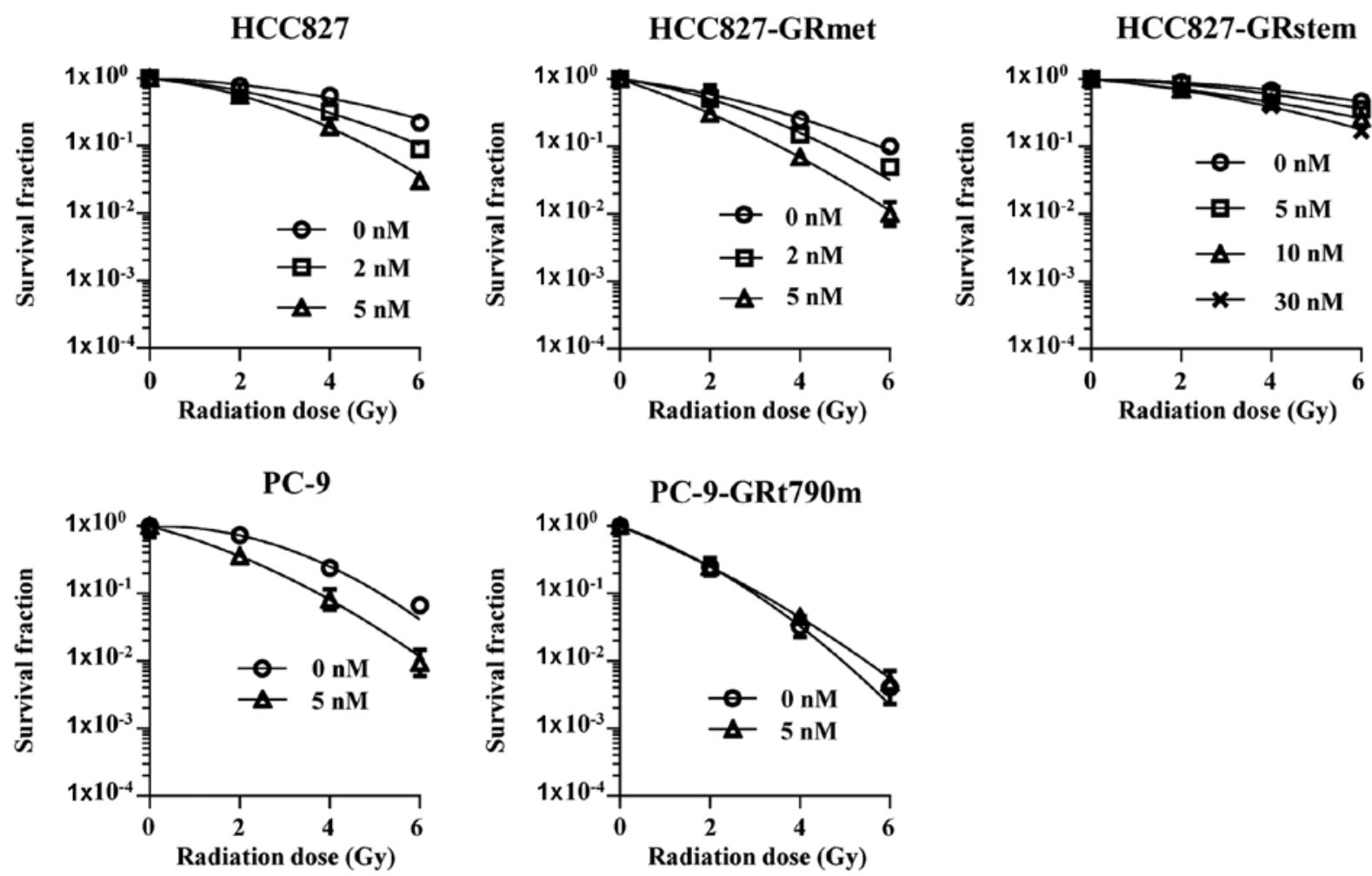

Figure 1. Survival curves of the clonogenic survival assays. Survival fractions indicate the ratio of the plating efficacy of the treated cells to the non-treated cells. Each symbol indicates the concentration of AUY. The cells were irradiated after exposure to AUY for $24 \mathrm{~h}$ and were plated into 6-well plates. The colonies were counted at 14 days after the IR. All experiments were performed at least three times and error bars indicate standard deviations.

were analyzed using GraphPad Prism, ver. 6.0.3, J (GraphPad Software, San Diego, CA, USA).

\section{Results}

$A U Y$ is effective for overcoming EGFR-TKI resistance in all of the cell lines examined, except for the cell line with stem cell-like properties. The $\mathrm{IC}_{10}$ and $\mathrm{IC}_{50}$ values of $\mathrm{AUY}$ in the parental cell lines and EGFR-TKI-resistant sublines are shown in Table I. HCC827-GRmet and PC-9-GRt790m cells were more sensitive to $\mathrm{AUY}$ than the parental cell lines. The $\mathrm{IC}_{50}$ value for HCC827-GRstem was over 20-fold as high as that for the other cell lines.

Radiosensitizing effect of AUY. The survival curves and parameters of the clonogenic cell survival assays are shown in Fig. 1 and Table II, respectively. The $\mathrm{D}_{10}$ values for HCC827GRmet or PC-9-GRt790m cells were lower than those for the parental cell lines, while the value for HCC827-GRstem was higher than that for the parental cell line. Therefore, these sublines were more sensitive to IR than the parental cell lines, except for HCC827-GRstem. Radiosensitization was defined as a ratio of the $D_{10}$ value for the control cells to that for the AUY-treated cells of $>1.5$. Our study revealed that both the parental cell line and HCC827-GRmet were radiosensitized, while HCC827-GRstem and PC-9-GRt790m were not radiosensitized by $5 \mathrm{nM}$ of AUY.

$G_{2} / M$ arrest is caused by IR with $A U Y$. The proportions of HCC 827 cells in the $\mathrm{G}_{2} / \mathrm{M}$ phase following exposure to only
IR and following exposure to both IR and AUY were 24 and $40 \%$, respectively. The proportions of HCC827-GRmet cells in $\mathrm{G}_{2} / \mathrm{M}$ phase following exposure to only IR and following exposure to both IR and AUY were 20 and $41 \%$, respectively. In brief, exposure to both IR and AUY caused $\mathrm{G}_{2} / \mathrm{M}$ arrest. However, in the case of the HCC827-GRstem cells, the proportion of cells in the $\mathrm{G}_{2} / \mathrm{M}$ phase following exposure to only IR and following exposure to both IR and AUY were 20 and $22 \%$, respectively. Therefore, HCC827-GRstem was resistant to $\mathrm{G}_{2} / \mathrm{M}$ arrest even after combined IR plus AUY treatment (Fig. 2).

DNA repair ability of the EGFR-TKI-resistant cell lines. Repair of DNA DSBs was evaluated by determining the decrease in the number of $\gamma \mathrm{H} 2 \mathrm{AX}$ foci (Fig. 3). The numbers of $\gamma \mathrm{H} 2 \mathrm{AX}$ foci in the HCC827 cells after only IR were $47.6 \pm 21.4$ and $32.7 \pm 28.8$ at 6 and $48 \mathrm{~h}$, respectively $(\mathrm{P}=0.01)$, while the corresponding values after exposure to both IR and AUY were $53.2 \pm 23.5$ and $46.9 \pm 37.4(\mathrm{P}=0.33)$. The numbers of $\gamma \mathrm{H} 2 \mathrm{AX}$ foci in the HCC827-GRmet cell line after only IR were $48.2 \pm 24.5$ and $37.3 \pm 24.5$ at 6 and $48 \mathrm{~h}$, respectively $(\mathrm{P}=0.02)$, and the corresponding values in the cells exposed to both IR and AUY were 48.2 \pm 22.7 and $57.8 \pm 23.1 \quad(\mathrm{P}=0.12$ ). Furthermore, the numbers of $\gamma \mathrm{H} 2 \mathrm{AX}$ foci in the HCC827GRstem cells exposed to IR alone were $45.4 \pm 23.2$ and $16.4 \pm 8.7$ at 6 and $48 \mathrm{~h}$, respectively $(\mathrm{P}<0.01)$, and the corresponding values in the cells exposed to both IR and AUY were 49.1 \pm 27.1 and 15.9 $\pm 9.7(\mathrm{P}<0.01)$. In the IR treatment group, HCC827 and HCC827-GRmet cells at $48 \mathrm{~h}$ showed a significant decrease in the numbers of $\gamma \mathrm{H} 2 \mathrm{AX}$ foci compared to those at $6 \mathrm{~h}$. However, 
Table II. Cloning efficiencies and radiosensitivity parameters.

\begin{tabular}{|c|c|c|c|c|c|c|}
\hline Cell lines & Plating efficiency & SF2 & $\alpha\left(\mathrm{Gy}^{-1}\right)$ & $\beta\left(\mathrm{Gy}^{-1}\right)$ & $\mathrm{D}_{10}(\mathrm{~Gy})^{\mathrm{b}}$ & $\mathrm{D}_{10}$ control/D $\mathrm{D}_{10}+\mathrm{AUY} 922$ \\
\hline $\mathrm{HCC} 827$ & $0.3 \pm 0.1$ & $0.78 \pm 0.12$ & $0.05 \pm 0.04$ & $0.03 \pm 0.01$ & 5 & - \\
\hline +2 nM AUY & $0.3 \pm 0.1$ & $0.65 \pm 0.04$ & $0.13 \pm 0.01$ & $0.04 \pm 0.004$ & 3.6 & 1.4 \\
\hline +5 nM AUY & $0.3 \pm 0.1$ & $0.56 \pm 0.02$ & $0.16 \pm 0.01$ & $0.01 \pm 0.003$ & 2.9 & 1.7 \\
\hline HCC827-GRmet & $0.4 \pm 0.1$ & $0.60 \pm 0.22$ & $0.19 \pm 0.01$ & $0.04 \pm 0.003$ & 3.3 & - \\
\hline +2 nM AUY & $0.4 \pm 0.02$ & $0.51 \pm 0.04$ & $0.22 \pm 0.03$ & $0.06 \pm 0.01$ & 2.6 & 1.2 \\
\hline +5 nM AUY & $0.2 \pm 0.01$ & $0.31 \pm 0.01$ & $0.5 \pm 0.01$ & $0.04 \pm 0.004$ & 1.7 & 1.9 \\
\hline HCC827-GRstem & $0.5 \pm 0.1$ & $0.90 \pm 0.25$ & $0.02 \pm 0.05$ & $0.02 \pm 0.01$ & 6.9 & - \\
\hline +5 nM AUY & $0.5 \pm 0.1$ & $0.84 \pm 0.17$ & $0.04 \pm 0.02$ & $0.02 \pm 0.01$ & 5.9 & 1.2 \\
\hline +10 nM AUY & $0.6 \pm 0.04$ & $0.71 \pm 0.08$ & $0.14 \pm 0.01$ & $0.01 \pm 0.005$ & 4.8 & 1.4 \\
\hline+30 nM AUY & $0.5 \pm 0.04$ & $0.68 \pm 0.02$ & $0.14 \pm 0.01$ & $0.02 \pm 0.003$ & 4.2 & 1.7 \\
\hline PC-9 & $0.85 \pm 0.27$ & $0.74 \pm 0.08$ & $0.03 \pm 0.1$ & $0.09 \pm 0.04$ & 3.4 & - \\
\hline +5 nM AUY & $0.06 \pm 0.01$ & $0.36 \pm 0.09$ & $0.4 \pm 0.1$ & $0.06 \pm 0.05$ & 2 & 1.8 \\
\hline PC-9-GRt790m & $0.4 \pm 0.1$ & $0.25 \pm 0.09$ & $0.5 \pm 0.4$ & $0.08 \pm 0.17$ & 1.5 & - \\
\hline +5 nM AUY & $0.2 \pm 0.02$ & $0.25 \pm 0.02$ & $0.6 \pm 0.2$ & $0.04 \pm 0.07$ & 1.5 & 1.0 \\
\hline
\end{tabular}

AUY, NVP-AUY922; SF2, surviving cell fractions at $2 \mathrm{~Gy} ; \mathrm{D}_{10}$, radiation doses required for $10 \%$ survival; $\mathrm{D}_{10}$ control/ $\mathrm{D}_{10}+\mathrm{AUY} 922$, ratio of $D_{10}$ of control to $D_{10}$ for each AUY concentration. Data are shown as the mean \pm standard deviation from at least 3 experiments.

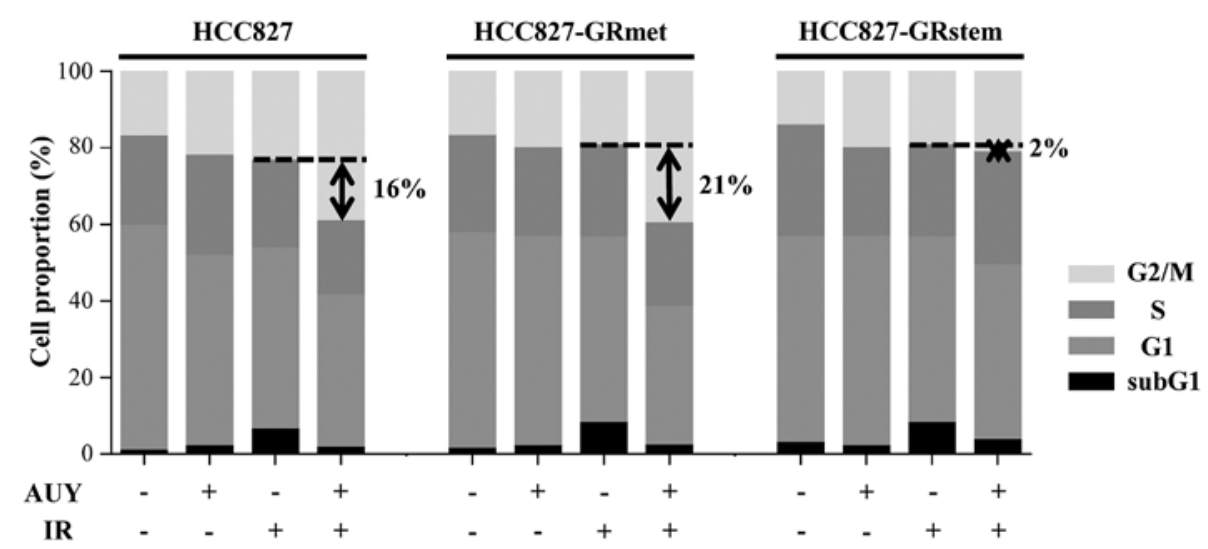

Figure 2. Effects of the combined treatment if IR and AUY on cell cycle distribution. The cells were irradiated at 6 Gy after exposure to $100 \mathrm{nM}$ of AUY for $24 \mathrm{~h}$, and were then harvested and analyzed at $48 \mathrm{~h}$ after the IR. The cell cycle distribution was determined by flow cytometry after propidium iodide staining. AUY, NVP-AUY922; IR, ionizing radiation.

in the IR plus AUY group, the significant difference was not achieved between the numbers of $\gamma \mathrm{H} 2 \mathrm{AX}$ at $6 \mathrm{~h}$ and those at $48 \mathrm{~h}$. In contrast HCC827-GRstem cells showed a significant decrease in the number of $\gamma \mathrm{H} 2 \mathrm{AX}$ foci after both IR treatment alone and after combined IR plus AUY treatment.

\section{Discussion}

In the present study, AUY was effective against EGFR-TKIresistant cells with secondary mutation of EGFR or other RTK dependence. These results are concordant with previous reports (15-17). We demonstrated that combined exposure to IR and AUY caused $\mathrm{G}_{2} / \mathrm{M}$ arrest and inhibition of DNA DSB repair, and radiosensitized EGFR-TKI-resistant cell lines with major resistance mechanisms such as T790M mutation and MET amplification. However, the DNA repair ability of the
EGFR-TKI-resistant cell line with stem cell-like properties was maintained even after combined treatment with IR and AUY, and the radiosensitizing effect of AUY on this cell line was limited.

Notably, the cell lines with acquired resistance to EGFRTKIs associated with T790M mutation or MET amplification were more sensitive to IR than the parental cell lines in our study. Das and colleagues showed that NSCLC with activating EGFR mutations were sensitive to IR (28). They proposed two possible mechanisms to explain this finding. i) Elevated or aberrant signaling from the mutant EGFR may override the IR-induced checkpoint. ii) Translocated EGFR binds to the promoter region of DNA-dependent protein kinase (DNA-PK) (29), while mutated EGFR may not be able to bind to it. Although the precise reasons for the greater radiosensitivity of the EGFR-TKI-resistant-sublines than that of the parental 


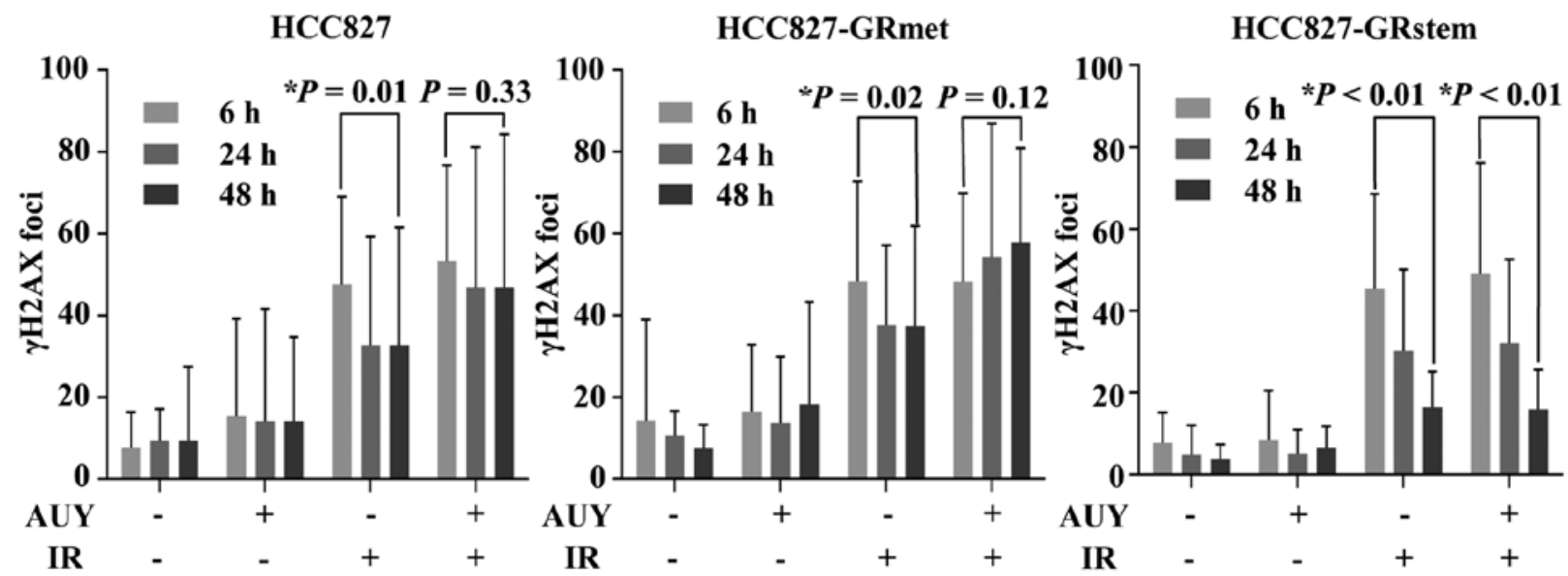

Figure 3. DNA DSB repair after IR. The numbers of $\gamma \mathrm{H} 2 \mathrm{AX}$ foci in each nucleus reflecting DNA DSBs are shown. The cells were irradiated at 6 Gy after exposure to $100 \mathrm{nM}$ of AUY for $24 \mathrm{~h}$, and stained by immunofluorescence staining; the number of $\gamma \mathrm{H} 2 \mathrm{AX}$ foci in the cells was then counted. Each symbol indicates the time point after IR. Error bars indicate the standard deviations. The numbers of $\gamma \mathrm{H} 2 \mathrm{AX}$ foci at $6 \mathrm{~h}$ after IR were compared to the numbers at $48 \mathrm{~h}$ after IR in each of the cells using the Mann-Whitney U test. * $\mathrm{P}<0.05$ (two-tailed). DSB, double strand breaks; AUY, NVP-AUY922; IR, ionizing radiation.

cell lines in our cohort could not be clearly elucidated, the acquired resistance mechanisms may have an influence. The signaling from amplified-MET may also override the IR-induced checkpoint, or secondary EGFR mutations such as the T790M mutation may also affect the binding of EGFR to the DNA-PK promoter.

Previously, several mechanisms to explain the radiosensitizing effect of Hsp90 inhibitors have been reported (18-21). IR causes $\mathrm{G}_{2} / \mathrm{M}$ arrest through the ATM-CHK pathway (30). As ATM and CHK are client proteins of Hsp90, Hsp90 inhibitors enhance the $\mathrm{G}_{2} / \mathrm{M}$ arrest caused by IR (23,31-33). Alternatively, Hsp90 inhibitors impair non-homologous end joining (NHEJ) through DNA-PK/ATM $(23,31,33-35)$. These phenomena were also shown in our cohort, except in the HCC827-GRstem cell line.

Cancer stem cells show activation of DNA DSB repair by NHEJ through the DNA-PK/ATM-CHK pathway, and several cancers, including NSCLCs, show radioresistance (35-38). HCC827-GRstem, an EGFR-TKI-resistant cell line with stem cell-like properties, also showed radioresistance and activation of DNA DSB repair. Therefore, it was expected that the Hsp90 inhibitor might allow the radioresistance of this cell line to be overcome, since DNA-PK, ATM and CHK are client proteins of Hsp90. However, combined treatment with IR and AUY of the HCC827-GRstem cell line produced neither $\mathrm{G}_{2} / \mathrm{M}$ arrest nor inhibition of DNA DSB repair.

As secondary mutations of EGFR or other RTK dependence accounts for EGFR-TKI resistance in over $60 \%$ of cases $(39,40)$, these can be defined as the major resistance mechanisms. Combined therapy with IR and AUY is a promising option to overcome these major EGFR-TKI resistances; on the other hand, other minor resistance mechanisms, such as those in cells with stem cell-like properties, require other approaches.

In conclusion, combined therapy with IR and AUY is effective to overcome major acquired resistance to EGFR-TKIs such as that associated with the T790M mutation or MET amplification, while the effect on resistance associated with stem cell-like properties of the cells was limited. Further investigation is warranted to elucidate the mechanism of acquired resistance to EGFR-TKIs associated with stem celllike properties of cells.

\section{Acknowledgements}

The authors thank Mr. Seiji Tabara and Mr. Hirofumi Uno (Department of Radiology, Okayama University Hospital) for irradiating the cell lines and Ms. Fumiko Isobe (Department of Thoracic, Breast and Endocrinological Surgery, Okayama University Graduate School of Medicine, Dentistry and Pharmaceutical Sciences, Okayama, Japan) for her technical support. This study was supported by a Grant-in-Aid for Scientific Research from the Ministry of Education, Culture, Sports, Science and Technology of Japan (grant no. 24791462 to H.Y.).

\section{References}

1. Jemal A, Bray F, Center MM, Ferlay J, Ward E and Forman D: Global cancer statistics. CA Cancer J Clin 61: 69-90, 2011.

2. Lynch TJ, Bell DW, Sordella R, et al: Activating mutations in the epidermal growth factor receptor underlying responsiveness of non-small-cell lung cancer to gefitinib. New Engl J Med 350: 2129-2139, 2004

3. Mitsudomi T, Morita S, Yatabe Y, et al: Gefitinib versus cisplatin plus docetaxel in patients with non-small-cell lung cancer harbouring mutations of the epidermal growth factor receptor (WJTOG3405): an open label, randomised phase 3 trial. Lancet Oncol 11: 121-128, 2010.

4. Sequist LV, Martins RG, Spigel D, et al: First-line gefitinib in patients with advanced non-small-cell lung cancer harboring somatic EGFR mutations. J Clin Oncol 26: 2442-2449, 2008.

5. Rosell R, Moran T, Queralt C, et al: Screening for epidermal growth factor receptor mutations in lung cancer. N Engl J Med 361: 958-967, 2009.

6. Mok TS, Wu YL, Thongprasert S, et al: Gefitinib or carboplatinpaclitaxel in pulmonary adenocarcinoma. N Engl J Med 361: 947-957, 2009.

7. Kobayashi S, Boggon TJ, Dayaram T, et al: EGFR mutation and resistance of non-small-cell lung cancer to gefitinib. $\mathrm{N}$ Engl $\mathrm{J}$ Med 352: 786-792, 2005.

8. Pao W, Miller VA, Politi KA, et al: Acquired resistance of lung adenocarcinomas to gefitinib or erlotinib is associated with a second mutation in the EGFR kinase domain. PLoS Med 2: e73, 2005.

9. Engelman JA, Zejnullahu K, Mitsudomi T, et al: MET amplification leads to gefitinib resistance in lung cancer by activating ERBB3 signaling. Science 316: 1039-1043, 2007. 
10. Shien K, Toyooka S, Yamamoto $\mathrm{H}$, et al: Acquired resistance to EGFR inhibitors is associated with a manifestation of stem cell-like properties in cancer cells. Cancer Res 73: 3051-3061, 2013.

11. Young JC, Moarefi I and Hartl FU: Hsp90: a specialized but essential protein-folding tool. J Cell Biol 154: 267-273, 2001.

12. Wright L, Barril X, Dymock B, et al: Structure-activity relationships in purine-based inhibitor binding to HSP90 isoforms. Chem Biol 11: 775-785, 2004.

13. Solit DB, Basso AD, Olshen AB, Scher HI and Rosen N: Inhibition of heat shock protein 90 function down-regulates Akt kinase and sensitizes tumors to Taxol. Cancer Res 63: 2139-2144, 2003.

14. Trepel J, Mollapour M, Giaccone G and Neckers L: Targeting the dynamic HSP90 complex in cancer. Nat Rev Cancer 10: 537-549, 2010.

15. Ueno T, Tsukuda K, Toyooka S, et al: Strong anti-tumor effect of NVP-AUY922, a novel Hsp90 inhibitor, on non-small cell lung cancer. Lung Cancer 76: 26-31, 2012.

16. Shimamura T, Li D, Ji H, et al: Hsp90 inhibition suppresses mutant EGFR-T790M signaling and overcomes kinase inhibitor resistance. Cancer Res 68: 5827-5838, 2008.

17. Koizumi H, Yamada T, Takeuchi S, et al: Hsp90 inhibition overcomes HGF-triggering resistance to EGFR-TKIs in EGFRmutant lung cancer by decreasing client protein expression and angiogenesis. J Thorac Oncol 7: 1078-1085, 2012.

18. Ha K, Fiskus W, Rao R, et al: Hsp90 inhibitor-mediated disruption of chaperone association of ATR with hsp90 sensitizes cancer cells to DNA damage. Mol Cancer Ther 10: 1194-1206, 2011

19. Kim WY, Oh SH, Woo JK, Hong WK and Lee HY: Targeting heat shock protein 90 overrides the resistance of lung cancer cells by blocking radiation-induced stabilization of hypoxia-inducible factor-1alpha. Cancer Res 69: 1624-1632, 2009.

20. Tse AN, Sheikh TN, Alan H, Chou TC and Schwartz GK: 90-kDa heat shock protein inhibition abrogates the topoisomerase I poison-induced G2/M checkpoint in p53-null tumor cells by depleting Chk1 and Wee1. Mol Pharmacol 75: 124-133, 2009.

21. Arlander SJ, Felts SJ, Wagner JM, Stensgard B, Toft DO and Karnitz LM: Chaperoning checkpoint kinase 1 (Chk1), an Hsp90 client, with purified chaperones. J Biol Chem 281: 2989-2998, 2006.

22. Lee JH, Choi KJ, Seo WD, et al: Enhancement of radiation sensitivity in lung cancer cells by celastrol is mediated by inhibition of Hsp90. Int J Mol Med 27: 441-446, 2011

23. Stingl L, Stuhmer T, Chatterjee M, Jensen MR, Flentje M and Djuzenova CS: Novel HSP90 inhibitors, NVP-AUY922 and NVP-BEP800, radiosensitise tumour cells through cell-cycle impairment, increased DNA damage and repair protraction. $\mathrm{Br}$ J Cancer 102: 1578-1591, 2010.

24. Gandhi J, Zhang J, Xie Y, et al: Alterations in genes of the EGFR signaling pathway and their relationship to EGFR tyrosine kinase inhibitor sensitivity in lung cancer cell lines. PLoS One 4: e4576, 2009.

25. Girard L, Zochbauer-Muller S, Virmani AK, Gazdar AF and Minna JD: Genome-wide allelotyping of lung cancer identifies new regions of allelic loss, differences between small cell lung cancer and non-small cell lung cancer, and loci clustering. Cancer Res 60: 4894-4906, 2000.
26. Kubo T, Toyooka S, Tsukuda K, et al: Epigenetic silencing of microRNA-34b/c plays an important role in the pathogenesis of malignant pleural mesothelioma. Clin Cancer Res 17: 4965-4974, 2011.

27. Rogakou EP, Pilch DR, Orr AH, Ivanova VS and Bonner WM: DNA double-stranded breaks induce histone $\mathrm{H} 2 \mathrm{AX}$ phosphorylation on serine 139. J Biol Chem 273: 5858-5868, 1998.

28. Das AK, Sato M, Story MD, et al: Non-small-cell lung cancers with kinase domain mutations in the epidermal growth factor receptor are sensitive to ionizing radiation. Cancer Res 66: 9601-9608, 2006.

29. Dittmann K, Mayer C, Fehrenbacher B, et al: Radiation-induced epidermal growth factor receptor nuclear import is linked to activation of DNA-dependent protein kinase. J Biol Chem 280: 31182-31189, 2005

30. Pawlik TM and Keyomarsi K: Role of cell cycle in mediating sensitivity to radiotherapy. Int J Radiat Oncol Biol Phys 59: 928-942, 2004.

31. Koll TT, Feis SS, Wright MH, et al: HSP90 inhibitor, DMAG, synergizes with radiation of lung cancer cells by interfering with base excision and ATM-mediated DNA repair. Mol Cancer Ther 7: 1985-1992, 2008.

32. Eccles SA, Massey A, Raynaud FI, et al: NVP-AUY922: a novel heat shock protein 90 inhibitor active against xenograft tumor growth, angiogenesis, and metastasis. Cancer Res 68: 2850-2860, 2008.

33. Stecklein SR, Kumaraswamy E, Behbod F, et al: BRCA1 and HSP90 cooperate in homologous and non-homologous DNA double-strand-break repair and G2/M checkpoint activation. Proc Natl Acad Sci USA 109: 13650-13655, 2012.

34. Bakkenist CJ and Kastan MB: DNA damage activates ATM through intermolecular autophosphorylation and dimer dissociation. Nature 421: 499-506, 2003.

35. Kastan MB and Lim DS: The many substrates and functions of ATM. Nat Rev Mol Cell Biol 1: 179-186, 2000.

36. Lundholm L, Haag P, Zong D, et al: Resistance to DNA-damaging treatment in non-small cell lung cancer tumor-initiating cells involves reduced DNA-PK/ATM activation and diminished cell cycle arrest. Cell Death Dis 4: e478, 2013.

37. Phillips TM, McBride WH and Pajonk F: The response of CD24(-/low)/CD44(+) breast cancer-initiating cells to radiation. J Natl Cancer Inst 98: 1777-1785, 2006.

38. Bao S, Wu Q, McLendon RE, et al: Glioma stem cells promote radioresistance by preferential activation of the DNA damage response. Nature 444: 756-760, 2006.

39. Oxnard GR, Arcila ME, Chmielecki J, Ladanyi M, Miller VA and Pao W: New strategies in overcoming acquired resistance to epidermal growth factor receptor tyrosine kinase inhibitors in lung cancer. Clin Cancer Res 17: 5530-5537, 2011.

40. Sequist LV, Waltman BA, Dias-Santagata D, et al: Genotypic and histological evolution of lung cancers acquiring resistance to EGFR inhibitors. Sci Transl Med 3: 75ra26, 2011. 